\title{
POSITIONING AND MAPPING LOCATIONS AND ROUTES OF EXTENDED VISIBILITY THROUGH GIS DIGITAL ELEVATION DATA
}

\author{
G.A. ACHILLEOS \\ National Technical University of Athens, Greece.
}

\begin{abstract}
It is common for people travelling for recreational purposes to want routes that present remarkable view, continuity in their viewshed with scenes that are unusual or rare for their everyday routine. Geographical Information System (GIS) routines today, embody the ability to calculate the viewshed and to combine visibility basic analysis with digital elevation data within their spatial database. In this paper, with the use of GIS applications and tools regarding elevation data management, we attempt to define parameters that will help us to position locations and routes which are suitable in terms of their viewshed range, and, further on, to present this information on a map. We then proceed to a case study at Attica Prefecture in Greece, where we examine cases of point and area locations as well as routes as it concerns their visibility.

Keywords: digital elevation model, extended visibility, GIS, line of sight, viewshed.
\end{abstract}

\section{INTRODUCTION}

The notion of visibility is closely related to the everyday routine of people since it is a process based on one of the five human senses, i.e. vision. It is common for people traveling for recreational reasons to want to follow a route that presents remarkable view and continuity of scenes in their viewshed which are either unusual or rare for their everyday life. Therefore, people in big cities, stressed by the picture of their densely structured environment, wish they have during their recreation hours, images of nature and, preferably, static ones which they usually enjoy. The same happens also in the places where they reside or where they stop for a break (hotel, cafeteria, tavern etc.), when again they desire a panoramic view to unfold in front of them, a view which should be rare. The notion of remarkable view is mostly related to the notion of extended visibility and, preferably, of the superiority of the observer's position in relation to the viewshed. The existence of maps, which, following the positioning of locations and routes presenting extended visibility, will present this information using the rules imposed and the means provided by cartography, would be a basic tool for planning landscape, spatially arranging activities and operations and designing the policy for the society's recreation.

Viewshed calculation from a given viewing point is nowadays one of the basic procedures carried out by Geographical Information System (GIS) which can manage elevation data [1]. This procedure has been extensively examined in literature by Fisher [1, 2], Travis et al. [3], Lee [4], De Floriani and Magillo [5] and Magillo et al. [6]. Specialised approaches of visibility analysis and viewshed calculation are found in the works of Caldwell et al. [7], Fowler et al. [8], O'Sallivan and Turner [9], Tsouchlaraki and Achilleos [10], Ying et al. [11], Sparkes and Kidner [12], Rios-Urban and Chasan [13], Skov-Petersen and Snizek [14], Athanson [15], Albanese [16], Randolph and Ray [17], Kim et al. [18], Jiang [19], Jude et al. [20] and Coll et al. [21]. Most of their works will be discussed further in this paper.

A general definition of the notion of visibility could be:

Visibility exists between two points on the earth's surface (viewing point and target point), when no other point interferes between them by intersecting the continuity of the line which connects these two points. 
In this paper, with the use of GIS applications and tools regarding elevation data management, we attempt to define parameters that will help us to position locations and routes which are suitable in terms of their viewshed range, and, further on, to present this information on a map. We then proceed to a case study at Attica Prefecture in Greece where we examine cases of point and area locations as well as routes, as it concerns their visibility.

\section{THE QUANTITATIVE SPATIAL DIMENSION OF VISIBILITY}

\subsection{Quantitative parameters of visibility}

The notion of visibility was initially examined with the appearance of Digital Elevation Models (DEMs) and GIS. The development of DEMs and GIS solved many problems related to difficult and repetitive calculations, providing the scientists the opportunity to better manage and utilise their time.

With the development of information technology, the demand for improving the viewshed calculation has been increasing in terms of speed and quality in the result. Attempts are currently made to find quality control methods.

With regard to the viewshed, table $\mathrm{V}$ is formed whose elements are $V_{i j}=1$ when $P_{i j}$ is visible from P; and $V_{i j}=0$ in the opposite case. The viewshed contains the areas of table $\mathrm{V}$ where $V_{i j}=1$.

While studying and analysing visibility by using DEM, finding the elements of table $\mathrm{V}$ alone is not enough.

To consider that an analysis covered a subject-matter fully and provided all necessary data that can help the researcher, it must also provide alternative methods that can meet his individual needs.

Fisher in 1995-1996 [1, 2] and De Floriani and Magillo in 1993 [5, 6] have proposed some of these alternative forms; these are horizons (primary and secondary) and offsets from the line of sight (local and global).

The primary horizon is known as the line of viewshed that separates the visible relief from the sky (skyline). It is the physical barrier beyond which the observer from a view point A has no visibility to any direction [1]. This characteristic may be very useful in the case of spatially arranged activities that have aesthetic impacts.

Secondary horizons are the lines beyond which the viewshed is interrupted horizontally (existence of 'not visible' area) and appears again close [1].

Offsets are defined as the elevation differences between the line of sight and the points of the relief. These offsets may be measured either by the lines of sight that connect the view point to the secondary horizons (local offsets), or by the line of sight that connects the view point to the primary horizon (global offsets).

This alternative visibility analysis may be useful in landscape analyses and in monitoring any visual impact due to the spatial arrangement of activities which should or should not be visible. Of particular use is the concept of the sign (+/-) of the offset (local or global) which defines the maximum or minimum permissible elevation limits of the activities. Therefore, for example, if an activity which should not extend beyond the skyline is placed on the relief, its maximum permissible elevation is the global offset in this location of the relief [1].

\subsection{Viewsheds}

Viewshed depends directly on the height at the viewing point. Usually, an increase of the observation height results in an increase of the surface area of the visible part of the viewshed. The factors affecting the accuracy of the viewshed are many, such as the accuracy of elevation data, the 


\begin{tabular}{|c|c|c|c|c|c|c|c|c|c|c|c|c|c|c|c|}
\hline & & & & & 3 & 2 & & & & & & & 0 & & \\
\hline 0 & & 0 & 0 & 3 & & & P & e & 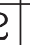 & & & & 10 & & 0 \\
\hline & & 0 & 3 & ट & & & & $\beta$ & 3 & E & & & 0 & & 0 \\
\hline & & 2 & 2 & & & & & & & & & 1 & 0 & & 0 \\
\hline 0 & & 2 & $\underline{0}$ & 0 & & & 4 & & & & & 1 & $\underline{0}$ & & 0 \\
\hline & & 0 & 0 & 0 & & & 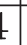 & 3 & & & J & 18 & $\overline{0}$ & & 0 \\
\hline & & 1 & 0 & 2 & & 4 & ¿ & 3 & 3 & 3 & & 21 & $\bar{z}$ & & 0 \\
\hline & & 2 & 3 & 3 & & & 2 & 3 & 2 & e & & 36 & 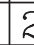 & & 0 \\
\hline 0 & & 0 & 3 & 3 & 3 & & & & 5 & 4 & & 26 & $c$ & & 0 \\
\hline 0 & & $\underline{\underline{u}}$ & 3 & 3 & & & & & 4 & & & $4 c$ & & 0 & 0 \\
\hline 0 & & 0 & & & & & & & & & & 01 & 1 & 1 & 0 \\
\hline 0 & & 0 & 0 & & & & & & 0 & & & & & & 0 \\
\hline & & & & & & & & & & & & & & & \\
\hline
\end{tabular}

Figure 1: 'Times seen' viewshed (black pixels are the view points).

accuracy of algorithm used, the procedure of decision-making on whether a position is visible or not, etc. $[14,17,22,23]$.

Calculating a viewshed is usually a time-consuming procedure. IT developments favour only a partial solution to the problem which still remains unsolved. Various algorithms have been developed in order to address the problem of time-consuming calculations by using 'intelligent' logic.

Many types of viewsheds have been devised and developed, in order to meet various needs.

Therefore, the typical viewshed where each point/pixel/triangle is determined as visible or not visible is a binary representation of the problem.

Another type of viewshed is the one called 'times seen viewshed' [2]. In this one, each point is codified in proportion to the number of times it is seen from the viewpoints (Fig. 1). This requires the existence of many viewpoints (more than one).

Another type of viewshed is the 'area seen viewshed map' [17]. Each point in the area of interest is examined as to the viewshed provided and is codified in proportion to the surface area of the wider region where it has visibility within a particular radius. One could easily identify from such maps the viewpoints that provide a long range of visibility.

A variant of this type [17] is the codification of each point of the area of interest on the basis of the direction on which lies the main part of its viewshed. In this way, one could easily identify points with long range of visibility and with particular direction.

New types/forms of viewsheds are the probabilistic viewsheds [2] and the fuzzy viewsheds [2] which do not determine their viewpoints as 'visible' or 'not visible' but provide either the possibility for a viewpoint to be probabilistic, or the value of the membership function in the viewshed (fuzzy). The author is developing an algorithm called GAVOS which calculates the probabilistic visibility in a different approach [23].

\subsection{Viewshed calculation algorithm}

In its generic form, the conventional traditional algorithm is the basic logic in all visibility calculation, viewshed and visibility analysis algorithms. What differentiates the existing algorithms is the technique for obtaining the data (view point location, target point location, elevations) and the decision-making technique for 'visible' or 'not visible' target points (Fig. 2). 


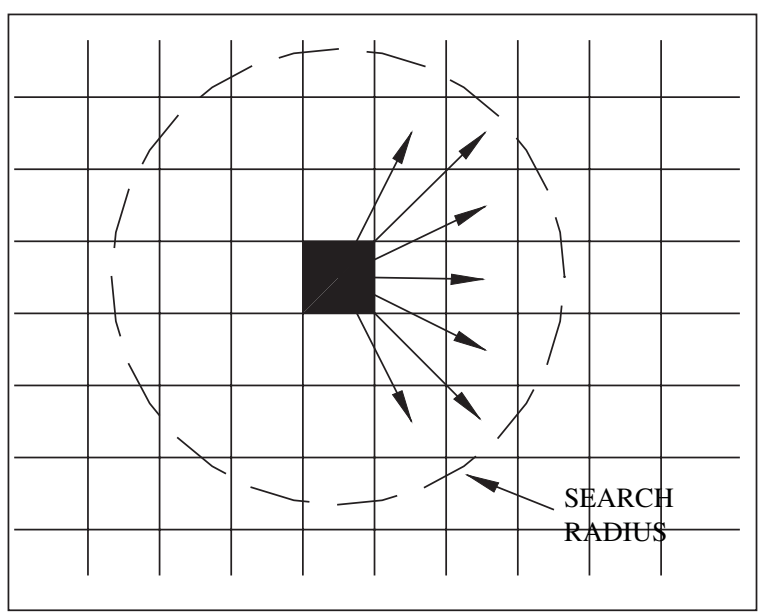

Figure 2: Basic viewshed calculation algorithm.

In the case of viewshed calculation, the algorithms are differentiated as to the process flow, the techniques used for reducing the calculation time and the techniques applied for optimising the quality of the results. The term 'traditional' distinguishes this algorithm from others which are conventional but also more 'intelligent' and flexible and definitely more suitable in some cases.

A traditional algorithm follows the basic principle of the generic conventional algorithm and its main characteristic is that the lines of sight are implemented in each target point separately. In the case of DEM, this is done for each pixel separately. Each target point is examined as 'visible' or 'not visible' and is codified accordingly with 1 or $0[1-3,5,24]$.

\section{THE QUALITATIVE SPATIAL DIMENSION OF VISIBILITY}

\subsection{Qualitative parameters of visibility}

Apart from the observer's ability to see or not from a particular location in space towards another specific area, another interesting and even more important factor is the way the observer sees this specific area.

The notion of remarkable view from an observation post is related to the notion of extended visibility (large visibility range) and, more preferably, of the superiority of the observer's position in relation to the viewshed $[25,26]$. With regard to the "value of a landscape with remarkable or no view, many research efforts have been made to estimate this 'value' in an objective way which also incorporates the point of view of the landscape's viewers. One of these research efforts resulted in mathematical models that, by using geometry parameters and parameters of image of a landscape which is presented in certain specially made metric photographs, could estimate the visual value that the viewers would give (average view) to the specific landscape [27, 28]. Another research [29] pointed out that through new approaches a significant result can be achieved in visibility studies (in certain case, modelling the phenomenon using neural networks).

There are many parameters that can be measured as quantitative, or are perceivable by the viewer as qualitative or sometimes are not at all perceivable. These parameters can be classified 
as follows [30]:

- Visibility parameters (viewing angle, visibility length, viewing elevation)

- Enclosed landscape parameters (degree of enclosure, depth of field)

- Open space parameters (space scale) etc.

Furthermore, an important parameter according to environment and landscape analysts is the distance from the viewing point. This distance is classified into three general categories of zones, namely,

$\begin{array}{ll}\text { close viewing zone } & <1 \mathrm{~km} \\ \text { middle viewing zone } & 1-5 \mathrm{~km} \\ \text { far viewing zone } & >5 \mathrm{~km} .\end{array}$

In the close and middle viewing zone, details and information can be perceived more easily by the observer as opposed to the far distance zone where the human eye cannot distinguish among details. Therefore, if the larger part of the viewshed lies within these zones, then the viewing point is better than the other which has its larger part of the viewshed in the far distance zone.

You may find more details on these parameters and on their calculation in the references in the end of the paper. In general, taking into account all these parameters, the viewshed analysis ends up to complex and time-consuming procedures. However, the result may help in designing activities, in avoiding visual impact and in selecting locations and routes that are interesting according to specific criteria [31-34].

\subsection{Defining the parameters}

The parameters that are used in this project which are applied easily and by using spatial analysis applications of a GIS are basic parameters that are calculated with the given DEM data (in other words, no perspective concepts are implied).

3.2.1 Cumulative viewshed of the sum of viewing points

If there is a sum of viewing points about which we are interested in calculating the cumulative viewshed, then the result is all the areas of the space of interest that are visible even from a single viewing point.

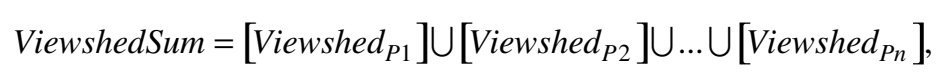

where ViewshedSum is the mathematical total of the partial viewsheds $i$ and Viewshed $_{P i}$ is the viewshed of viewpoint $i$.

This parameter distinguishes the total number of areas of the space of interest which are not visible from any viewing point (namely, those that are invisible to the observers).

3.2.2 Slope of the line of sight from the viewing point

Many times the question is to calculate the qualitative parameter of the viewshed which defines the superiority or not of the observer in relation to the entire area of interest that is perceivable.

Moreover, it is useful to have information which can directly define the elevation level on which a part of the visible area is found in relation to the elevation level of the viewing point (or points). 
Such information could be the slope of the line of sight towards each point in the space of interest and always in relation to the viewing point. This slope is calculated for each point within the space and is mapped.

$$
\text { Slope_VIS_Line }=\left(H_{V P}-H_{I}\right) / \operatorname{Dist}_{(V P-i)} \text {, }
$$

where Slope_VIS_Line is the calculated slope for the line of sight, $H_{V P}$ is the elevation of viewpoint, $H_{i}$ is the elevation of examined point $i$ and Dist is the distance from viewpoint VP to examined point $i$.

3.2.3 Percentage viewshed of the sum of viewing points

Another important basic parameter in viewshed analysis is the concept of percentage viewshed. If the viewing point is not one but many (either forming in combination a linear element or a surface one), then certain areas in the space of interest are not at all visible from any of the viewing points, some other areas are visible from all viewing points and the remaining areas are partially visible from the sum of the viewing points. If the concept of the viewing point (ViewPoint) and the target point (TargetPoint) is reversed, then each area 'has view' to a part of the sum of viewing points, or in other words, 'has view' to a percentage of the sum of viewing points.

This parameter is very useful when visibility is analysed in case of a spatial arrangement of activities that 'harm' the visual environment. In this case, it is possible to identify the areas from which the activity space is visible and to what percentage of the whole space it happens.

$$
\text { PercView }=\frac{\sum \text { visible_VPs }}{\sum V P s},
$$

where PercView is the percentage of viewpoints visible with the examined point, $\sum$ visible_VPs are the total of visible viewpoints from the examined point and $\Sigma V P s$ are the total of viewpoints.

3.2.4 Distribution of the viewshed from a single point or sum of viewing points This parameter defines the percentage of the viewshed of a single viewing point or of the sum of viewing points which is located within each distance zone from the observation post.

$$
\text { DistPercView }=\frac{\text { Viewshed_ZONE }_{i}}{\sum_{i=1}^{3} \text { Viewshed_ZONE }_{i}},
$$

where DistPercView is the percentage of viewshed area within each distance zone from the observation point, Viewshed_ZONE $E_{i}$ is the area of viewshed within distance zone $i$ and $\sum$ Viewshed_ZONE $E_{i}$ is the total area of viewshed.

\section{VIEWSHEDS ANALYSIS}

In this paper, we use the Prefecture of Attica as the area of interest and all the analysis and implementation of the investigations will take place in this area. We use a DEM which derived from the elevation data of a scale 1:50,000 (contours every $20 \mathrm{~m}$ and every $10 \mathrm{~m}$ in cases of nearly flat areas) (Fig. 3).

\subsection{Case 1: Viewshed of local element}

In the first investigation, we used the concept of viewing point (ViewPoint). Four viewing points are defined (Fig. 3) in the area (Mount Egaleo, Mount Parnitha, Mount Penteli, Mount Ymittos), and we 


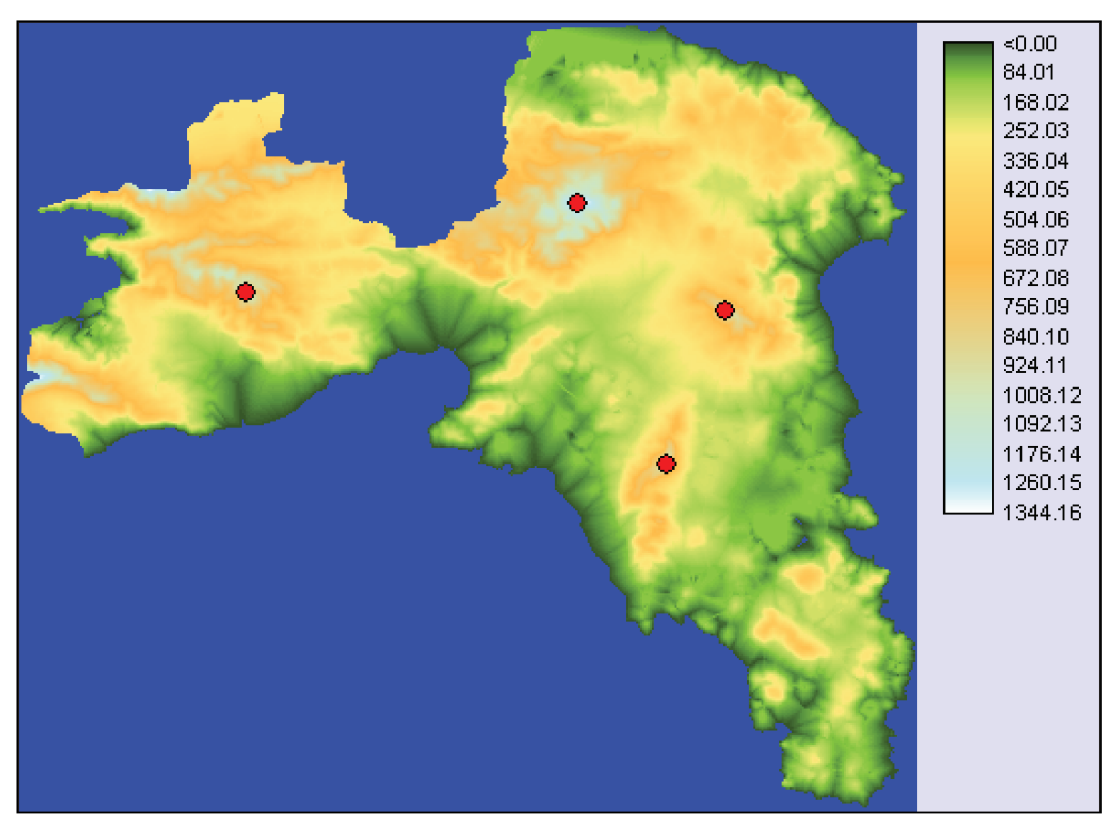

Figure 3: Digital Elevations Model of Prefecture of Attica with the selection of the four viewing points.

examined them either separately (Figs 4-7) or as a group of viewing points (Fig. 8) and their viewshed is analysed.

Their cumulative viewshed (Fig. 8) as well as their percentage viewshed (Fig. 9) is calculated.

Following this, the slope of the line of sight is calculated for each of the viewing points that are selected and this size is mapped (Figs 10-12).

Finally, after having calculated the distance from the viewing point for each of the four points selected (e.g. as in Fig. 10), the three distance zones are defined and the distribution of their viewshed is calculated (Table 1).

\subsection{Case 2: Viewshed of linear element}

In case the viewing points are the locus that implements the linear element, then the investigation follows nearly the same logic as in the first case (ViewPoint). The linear element is seen as a viewing line (ViewLine). This line is seen as continuous viewing points and the final result is collected and forms the result of the viewing line.

Examples of linear viewing elements (ViewLines) can be roads and railway tracks which cross through areas of particular interest and remarkable beauty. Also, examples are routes that pass through areas of strongly degraded visual environment and which are desirable to present the minimum viewshed. Linear elements which occupy a relatively important zone range and which should not be visible from the area they cross, as for example, high voltage electrical power transmission lines, big highways with an important number of earthworks (trenches, landfills) are investigation examples of this case.

The viewing line is selected (road route) and the distance of each point of the area of interest is calculated from this line (Figs 13, 14). 


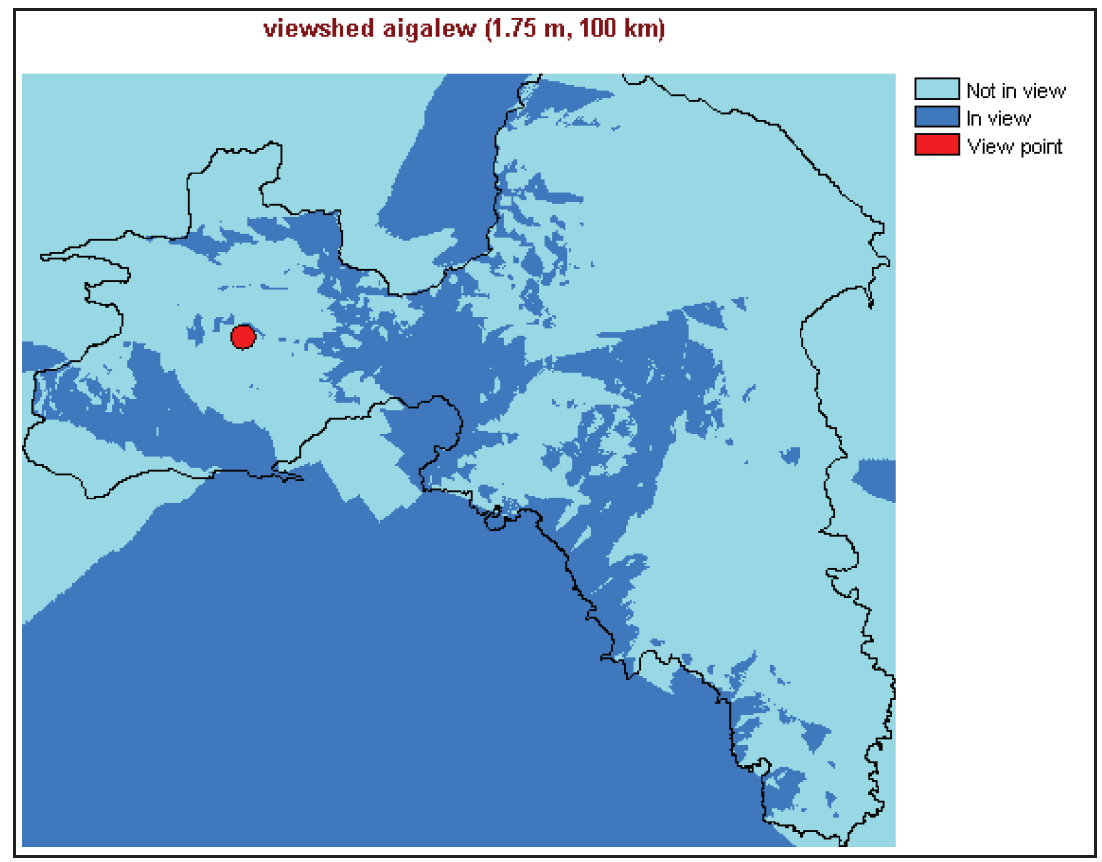

Figure 4: Viewshed of ViewPoint Mount Egaleo.

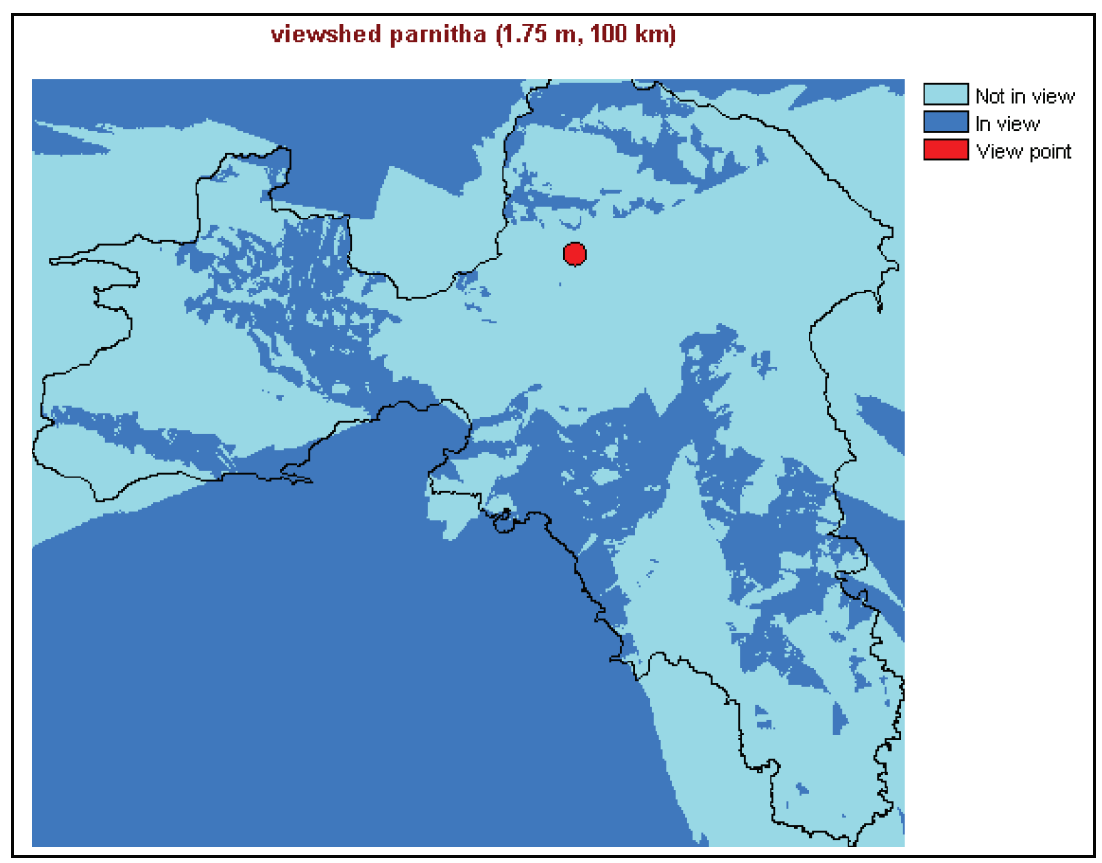

Figure 5: Viewshed of ViewPoint Mount Parnitha. 


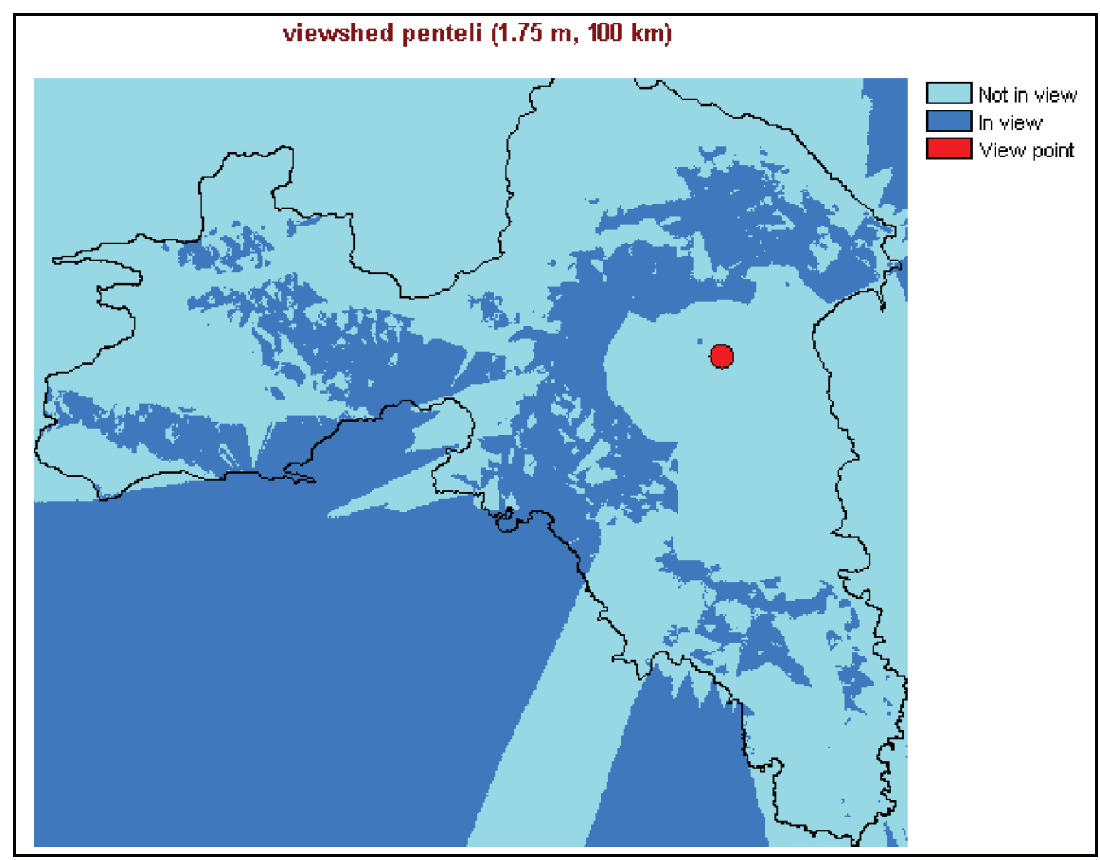

Figure 6: Viewshed of ViewPoint Mount Penteli.

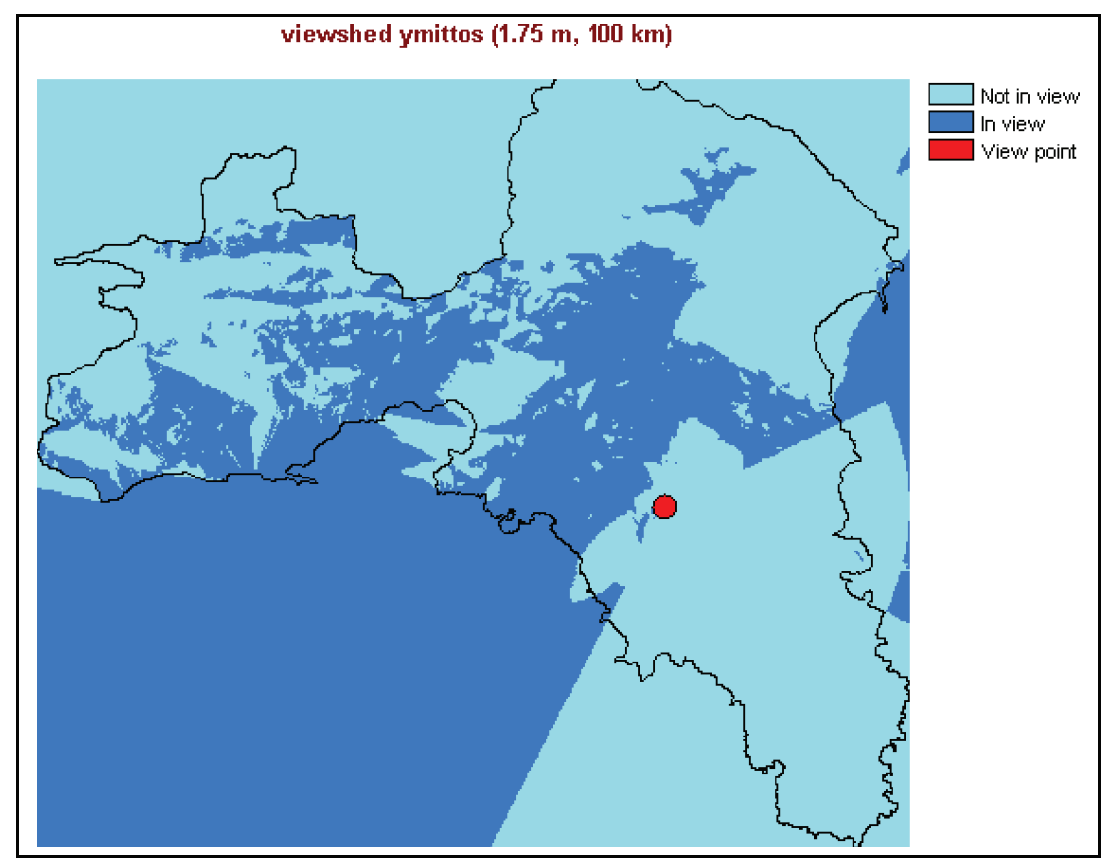

Figure 7: Viewshed of ViewPoint Mount Ymittos. 


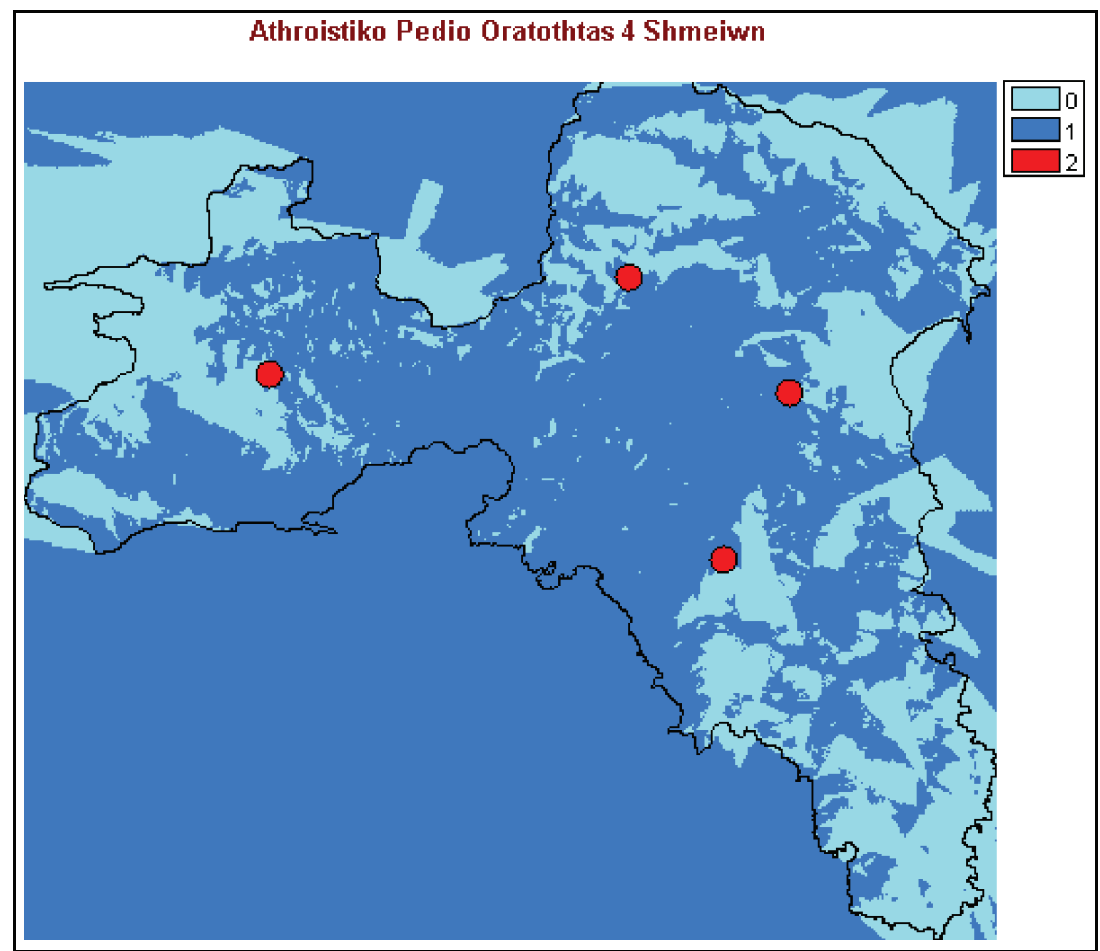

Figure 8: Cumulative viewshed of the sum of the four ViewPoints (ViewshedSum).

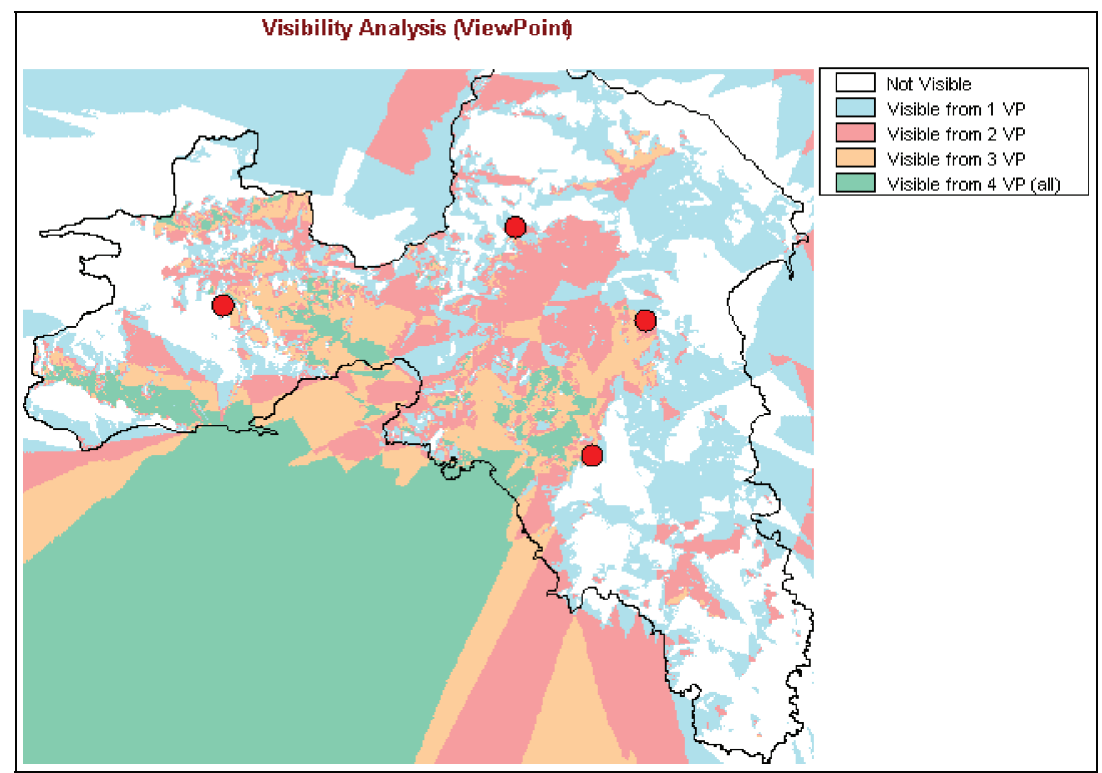

Figure 9: Percentage viewshed of the sum of the four ViewPoints (PercView). 


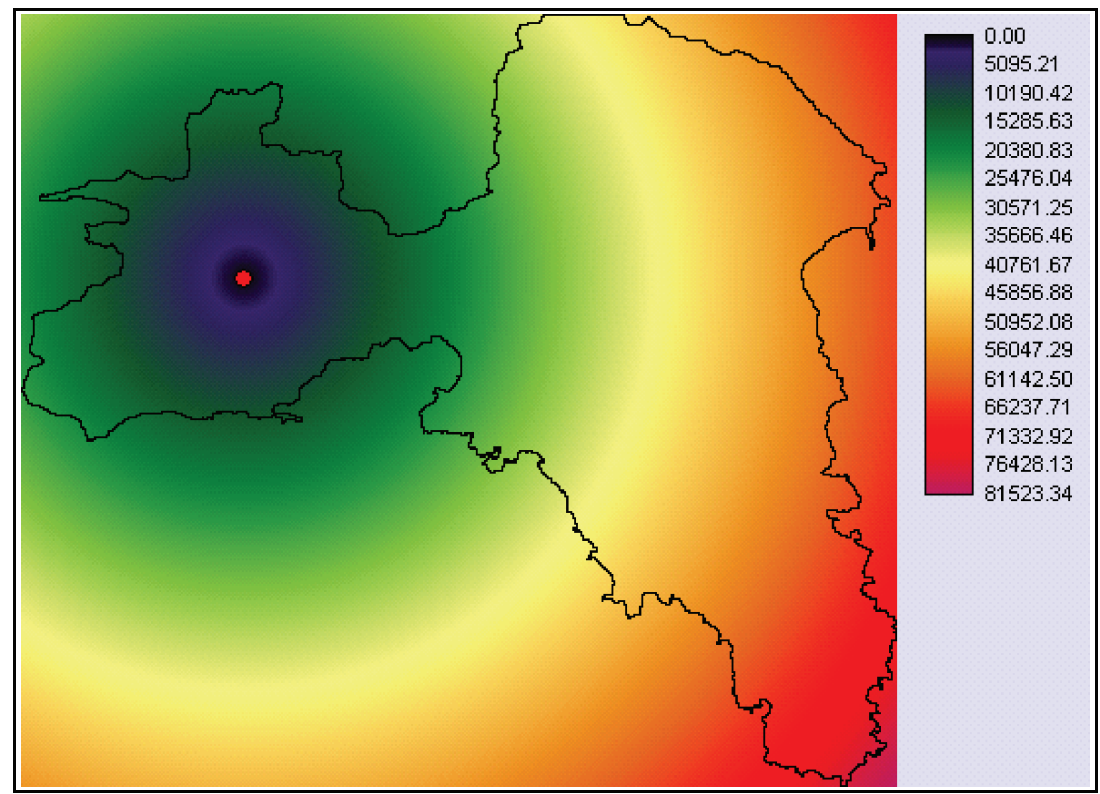

Figure 10: Distance from the ViewPoint Mount Egaleo.

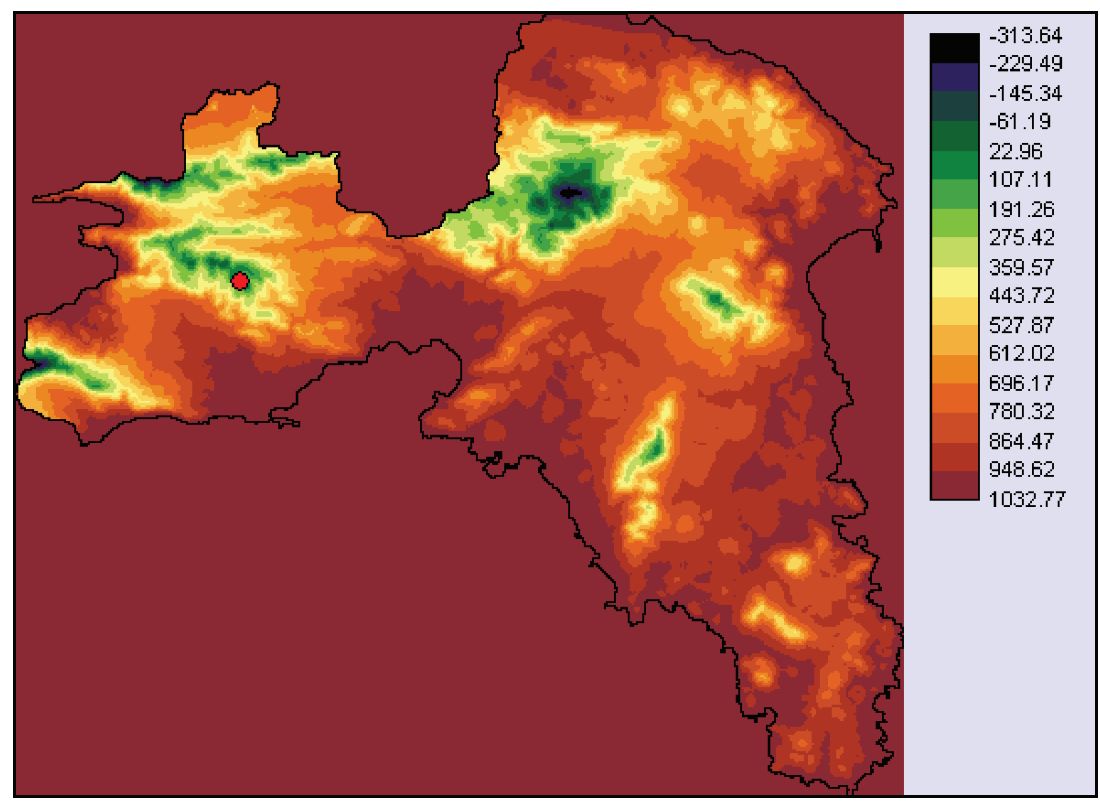

Figure 11: Elevation difference from the ViewPoint Mount Egaleo. 


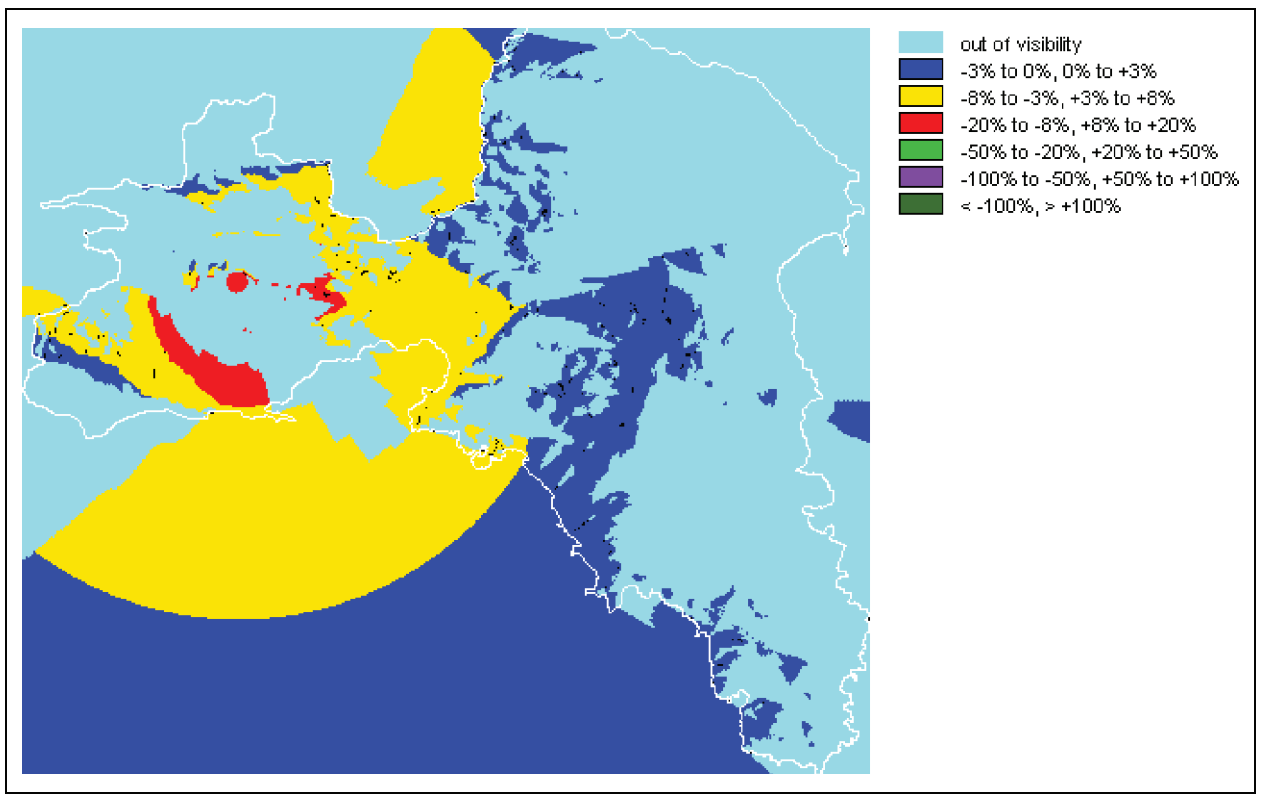

Figure 12: Slope of the line of sight of the ViewPoint Mount Egaleo.

Table 1: Distribution of viewshed of local element.

\begin{tabular}{lccc}
\hline View point & Close zone $(\%)<1 \mathrm{~km}$ & Middle zone $(\%) 1-5 \mathrm{~km}$ & Far zone $(\%)>5 \mathrm{~km}$ \\
\hline VP Egaleo & 0.02 & 0.18 & 99.81 \\
VP Parnitha & 0.01 & 0.11 & 99.89 \\
VP Penteli & 0.00 & 0.01 & 99.98 \\
VPYmittos & 0.03 & 0.50 & 99.48 \\
\hline
\end{tabular}

After the viewshed is calculated separately for each point of the locus defining the route, their cumulative viewshed (Fig. 15) as well as their percentage viewshed (Fig. 16) is calculated.

In the second case of investigation, the calculation of the slope of the line of sight cannot be effected for the viewing line, given that there is no single elevation based on which the elevation differences could be calculated. What perhaps could be possible is to calculate a mean elevation and use it as the basic elevation; but given the length of this route in combination with the intense alteration of elevations, such a solution would not contribute enough to the investigation.

However, the distribution of the line of sight is calculated from the route of interest, which presents the following results (Table 2).

\subsection{Case 3: Viewshed of surface element}

The third case concerns the viewshed analysis of surface elements that occupy an important area and, therefore, cannot be regarded as local. Such cases may include open mines, sanitary landfill sites, inert material mining sites, areas of heavy industrial activities which should not be visible. Respectively, there are other cases where it is desirable that they are visible if possible from the 


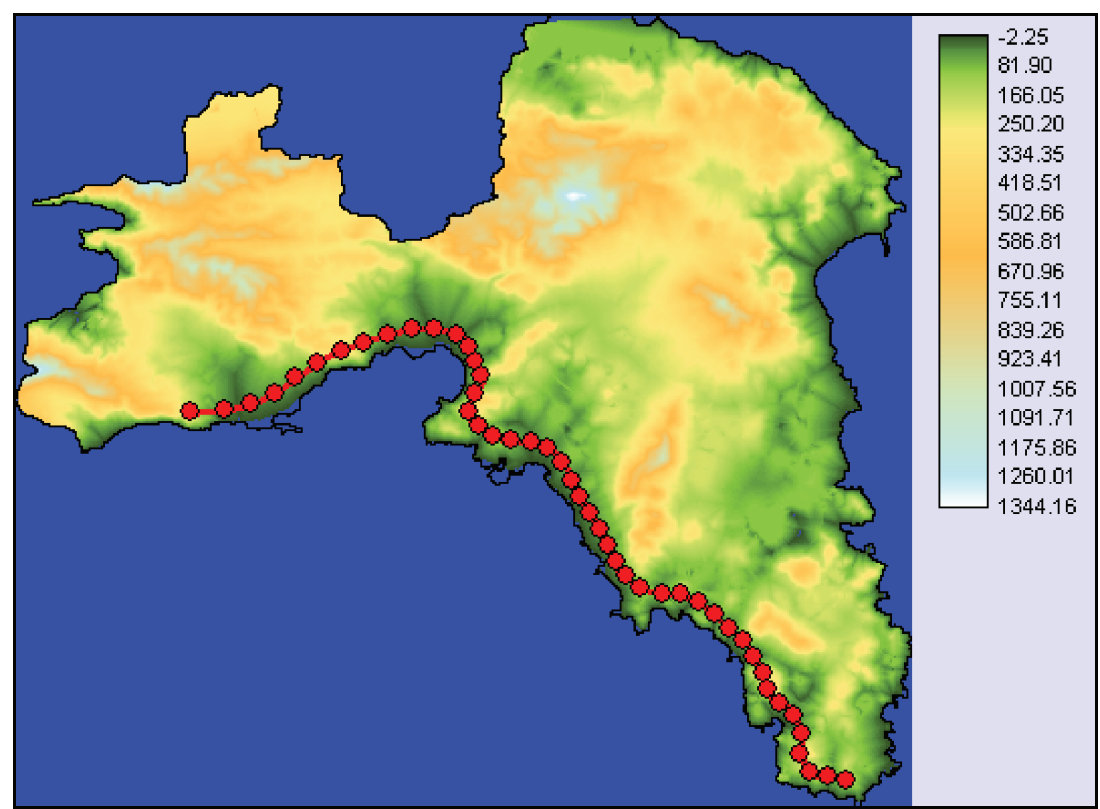

Figure 13: Selection of the viewing line (ViewLine).

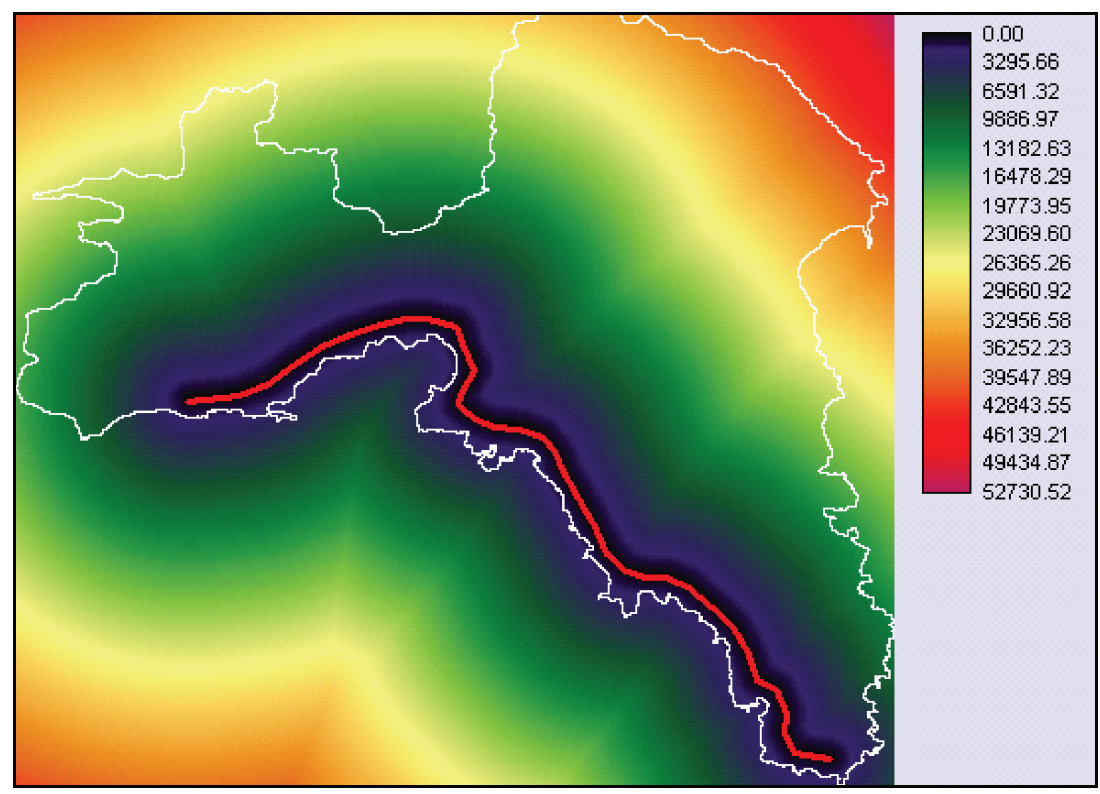

Figure 14: Distance from the viewing line (ViewLine). 


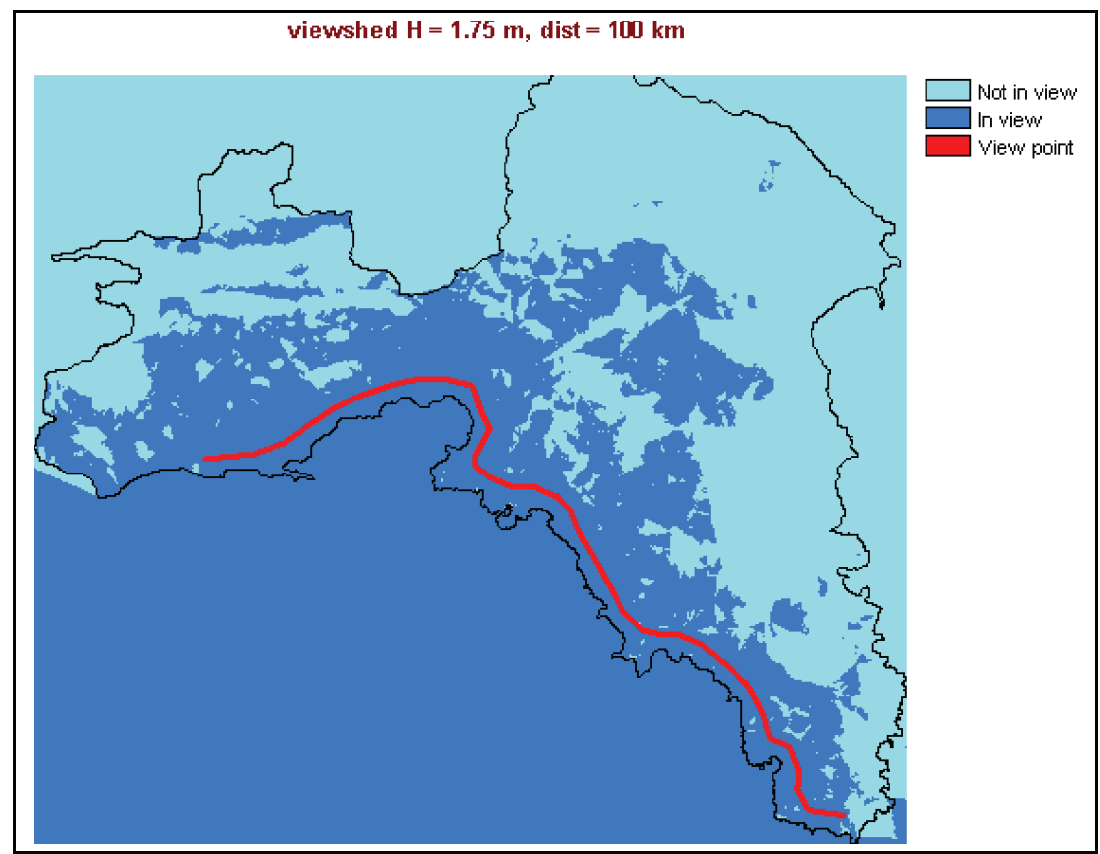

Figure 15: Cumulative viewshed of total viewing line (ViewshedSum).

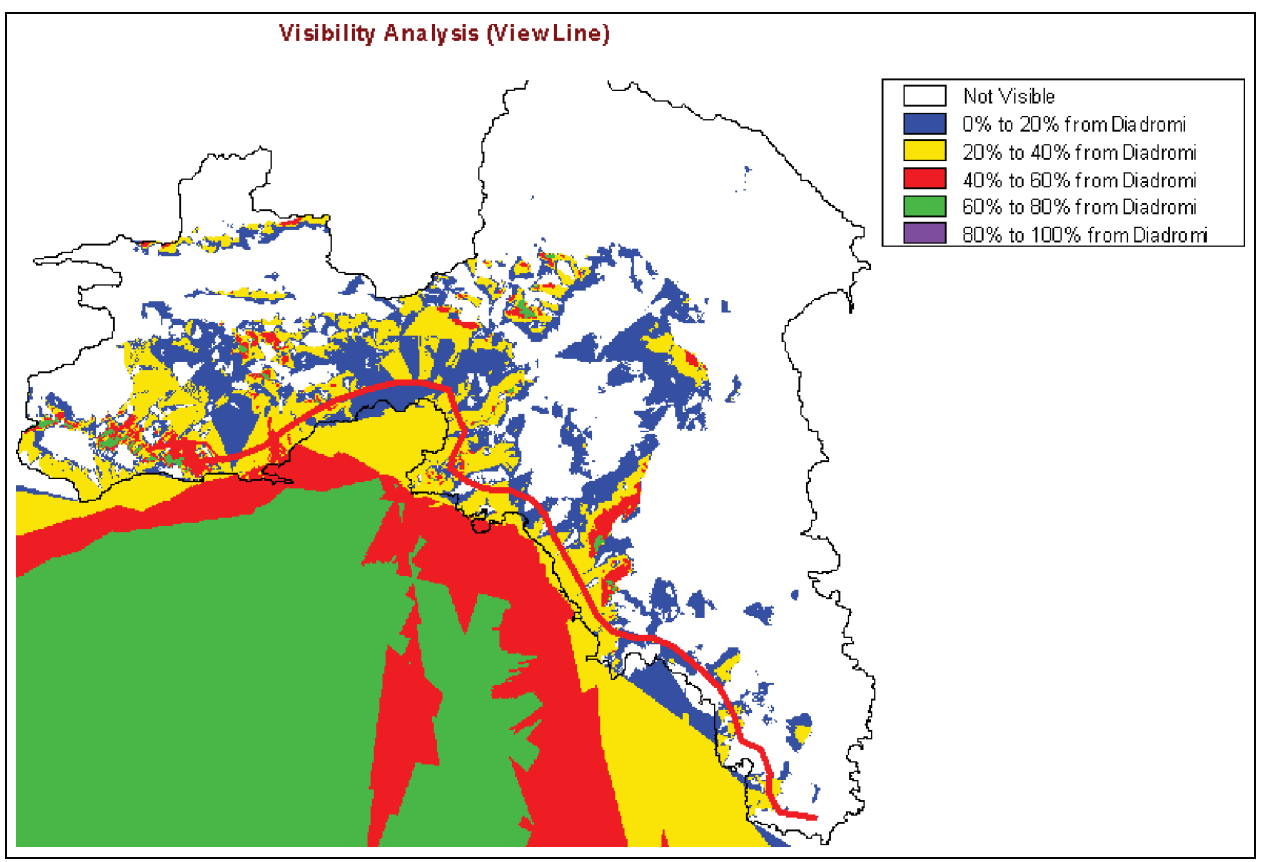

Figure 16: Percentage viewshed of the viewing line (PercView). 
Table 2: Distribution of viewshed of linear element.

\begin{tabular}{lccc}
\hline View point & Close zone $(<1 \mathrm{~km}) \%$ & Middle zone $(1-5 \mathrm{~km}) \%$ & Far zone $(>5 \mathrm{~km}) \%$ \\
\hline Route & 5.31 & 19.45 & 75.25 \\
\hline
\end{tabular}

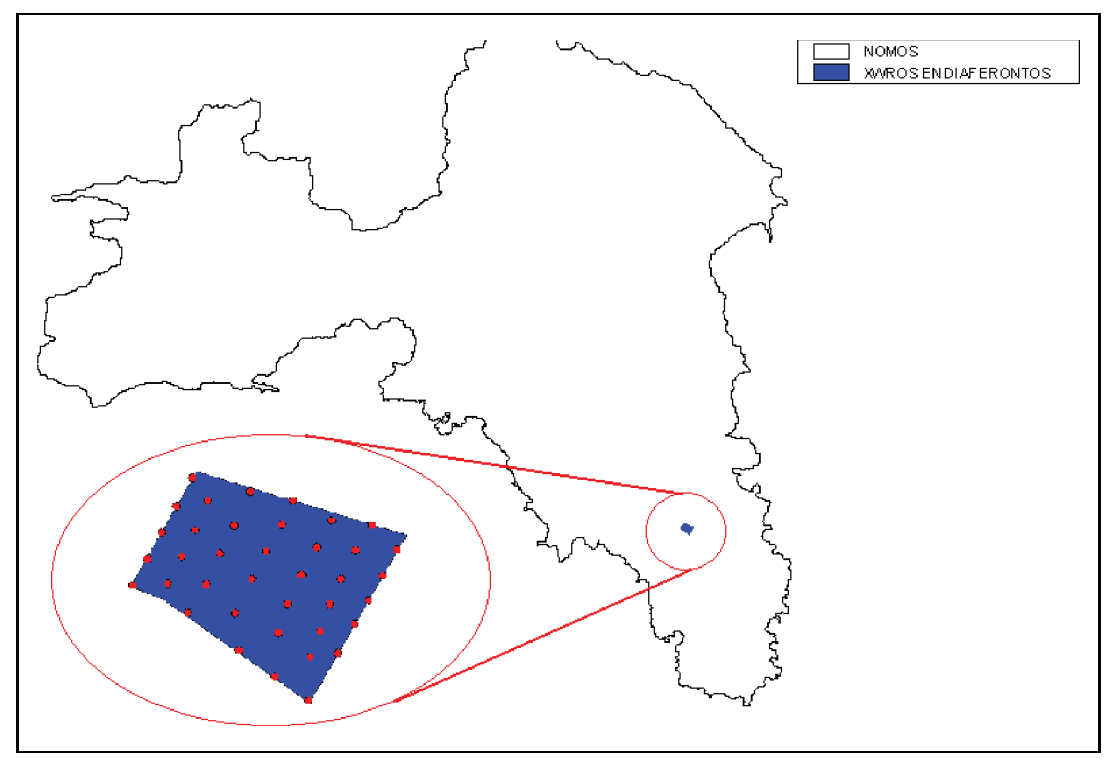

Figure 17: Selection of the viewing area (ViewArea).

entire area of interest, e.g. an amusement park, a lake with a remarkable visual shore environment and a coastal zone with significant view.

As in the second case, it is not possible to calculate the slope of the line of sight because the area of the surface element is not located at a single elevation which could be used as the reference elevation. Again, a mean elevation could be used if this parameter was desirable.

The surface element is selected, as shown in Fig. 17, and its cumulative viewshed (Fig. 18), as well as its percentage viewshed (Fig. 19), is calculated.

The calculation of the distribution of the viewshed from the area of interest gives the following results (Table 3 ).

\section{OBSERVATIONS AND COMMENTS}

It is obvious from literature that viewshed is not just an examination of the elevation information of the type 'higher' or 'lower', or having a direct conclusion such as 'visible' or 'not visible'. It is a much more complicated procedure defined by many parameters [2, 3, 9, 14, 17-19, 22, 24].

Within this paper, we attempt to define some parameters that will help us to position locations (points and areas) as well as routes based on some visibility criteria. These criteria include both quantitative and qualitative dimensions. It is something that ought to be done as people judge view and visibility in a more aesthetic way than mathematics. The need for tools which can simulate the public way of evaluation of scenery has been mentioned often in bibliography [7, 10, 12, 13, 16, 20, 21, 28]. 


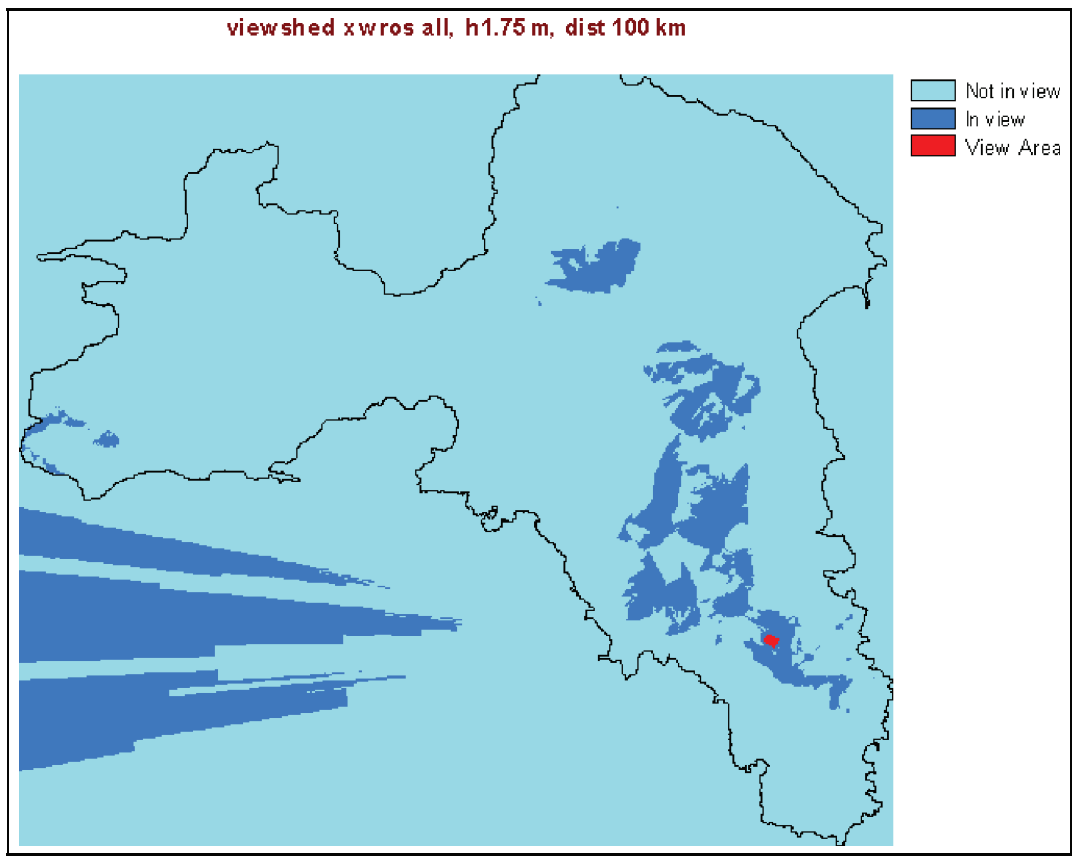

Figure 18: Cumulative viewshed of entire viewing area (ViewshedSum).

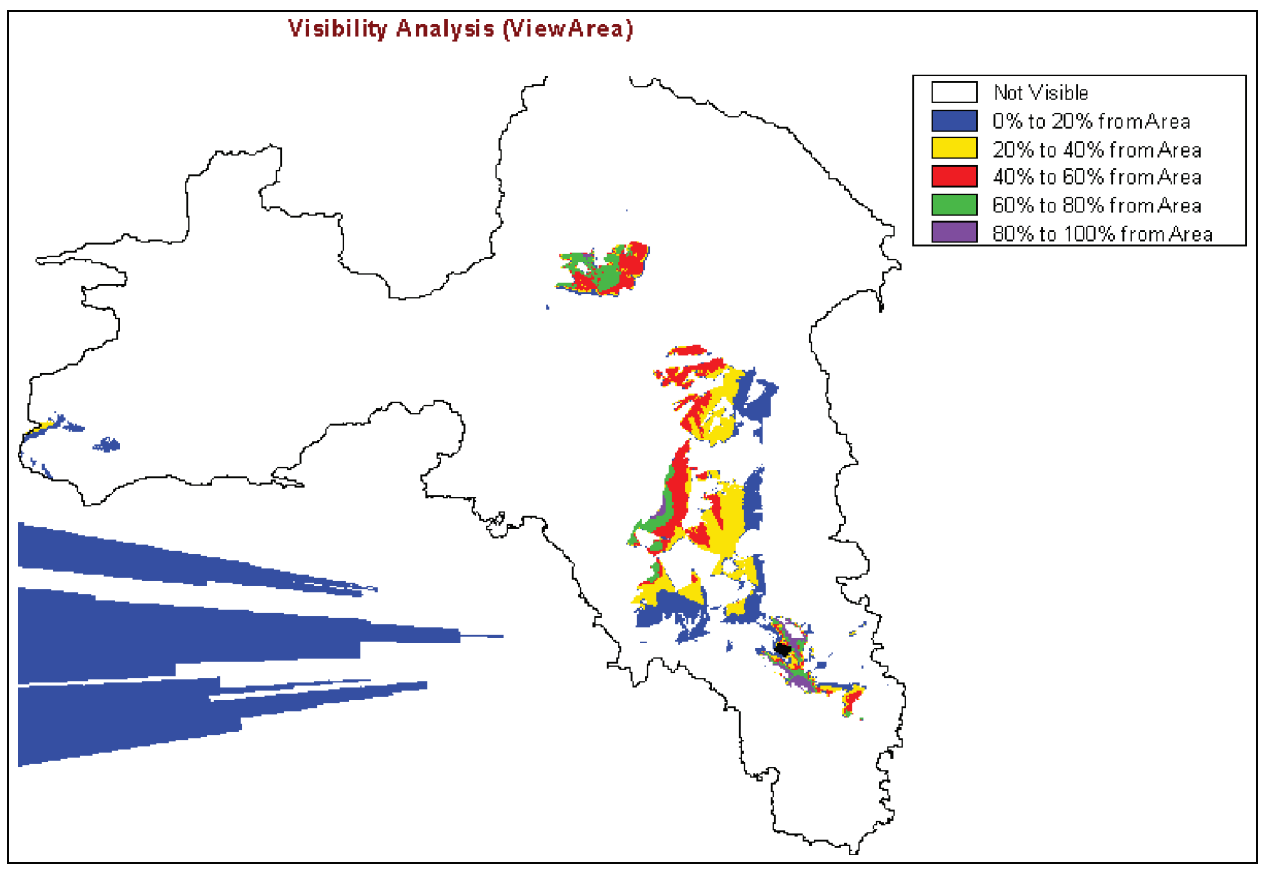

Figure 19: Percentage viewshed of viewing area (PercView). 
Table 3: Distribution of viewshed of surface element.

\begin{tabular}{lccc}
\hline View point & Close zone $(<1 \mathrm{~km}) \%$ & Middle zone $(1-5 \mathrm{~km}) \%$ & Far zone $(>5 \mathrm{~km})$ \\
\hline Viewing area & 1.14 & 3.41 & 95.45 \\
\hline
\end{tabular}

We then proceed to a case study at Attica Prefecture in Greece where we examine cases of point and area locations as well as routes as it concerns their visibility. Four points on mountaintops in the study area were selected, a route following the coastal zone and an area where a sanitary landfill site is planned to be constructed.

In these investigations, it is obvious that viewsheds are an unpredictable procedure. When examining the cases of the four local elements, we observe that in the case of Parnitha, which is located at a higher elevation, there is no larger viewshed. Moreover, this local element does not present the highest percentage viewshed within the first two landscape distance zones.

Another observation about the local element VP Egaleo is the picture it presents with regard to the slope of the line of sight. Due to the superiority of this point in relation to its surrounding area, the majority of the slopes of the line of sight lies at the first category, i.e. nearly horizontal.

The percentage viewshed of the four viewing points defines the sea and a few more areas surrounded by these four points as the areas which are visible from the majority of these points. Almost all the areas of the space of interest are visible from at least one point of the four local elements.

In comparison among the local elements, with regard to the distribution of their viewshed, it seems that VP Egaleo is better, given that it presents a nearly higher percentage of its viewshed within the close and middle distance zone from the viewing point.

Further on, with regard to the linear element (the route), it is observed that as the cumulative viewshed it covers almost the entire zone which is surrounded from the sea and the mountaintops that set the basin boundaries. The percentage viewshed of the route presents the following interesting characteristic. The morphology of the zone which this route crosses gives the possibility that the route is visible from a high percentage of areas within this zone (up to 40\%). When the elevation increases, the percentage of the route that is visible is limited. Furthermore, this route is visible almost in its entirety, nearly from every area of the sea. Caldwell and others [7] have mentioned this approach to separate routes that are completely invisible, completely visible or partially visible.

Finally, the space located southwest of the prefecture and that has been selected as a surface viewing element is visible from a small percentage of the area of interest. Its cumulative viewshed is limited in the area east of Ymittos and barely on a slope of Parnitha. Of course, the slope of Parnitha, although it typically has visibility to this surface element, in fact this is not possible due to the long distance. The same happens with a small area west of Egaleo.

The percentage viewshed for this area (surface element) shows that the areas which can see the space at a large percentage are located on high elevation on the slope of Ymittos. The 'area seen' as a percentage has also been mentioned by Caldwell and others [7], as a percent target visible parameter.

These observations are useful in many application cases. If, for example, we would like to monitor the sea area of Argosaronikos, we should select locations - points or a route - which could provide us with the maximum coverage in the area of Argosaronikos. In cases in which we would like to spatially arrange activities that create reactions from the public due to visual degradation, then we identify areas that are not visible from nowhere in the area or that are at least slightly visible.

In general, visibility analysis may be useful a priori to prevent impact and reactions, and to design and spatially arrange activities of interest at the optimum location as to the visual parameter. 
Further, this research will try to combine uncertainty with these new suggested parameters to attempt to offer to the development analysts and planners - tools really useful for their decision role.

\section{REFERENCES}

[1] Fisher, P.F., Reconsideration of the viewshed function in terrain modelling. Geographical Systems, 3, pp. 33-58, 1996.

[2] Fisher, P.F., An exploration of probable viewsheds in landscape planning. Environment and Planning B: Planning and Design, 22, pp. 527-546, 1995.

[3] Travis, M.R., Elsner, G.H., Iverson, W.D., Johnson, C.G., VIEWIT: computation of seen areas, slope and aspect for land-use planning. General technical report PSW - 11/1975 (\#Excerpt), Pacific Southwest Forest and Range Experiment Station, USDA, Forest Service, USA, 1975.

[4] Lee, J., Digital analysis of viewshed inclusion and topographic features on digital elevation models. Photogrammetric Engineering \& Remote Sensing, 60(4), pp. 451-456, 1994.

[5] De Floriani, L. \& Magillo, P., Computing visibility maps on a digital terrain model. Proceedings of European Conference, COSIT '93, Spatial Information Theory - A Theoretical Basis for GIS, eds. A. Frank \& I. Campari, Italy, September 1993, pp. 248-269, 1993.

[6] Magillo, P., De Floriani, L. \& Bruzzone, E., Updating visibility information on multiresolution terrain models. Proceedings of European Conference, COSIT '93, Spatial Information Theory - A Theoretical Basis for GIS, eds A. Frank \& I. Campari, Italy, September 1993, pp. 279-296, 1993.

[7] Caldwell, D.R., Mineter, M.J., Dowers, S. \& Gittings, B.M., Analysis and visualization of visibility surfaces. Proceedings of the 7th International Conference on GeoComputation, UK, 8-10 September 2003.

[8] Fowler, T., Pocemich, M., Braid, J., Holmes, A. \& Bateman, R., Quality assessment of the national ceiling and visibility analysis product. Joint Session 1. Calibration and Verification of Probabilistic Forecast Products (Joint between 12th Conference on Aviation Range, Aerospace Meteorology and the 18th Conference on Probability and Statistics), 1 February 2006.

[9] O' Sallivan, D. \& Turner, A., Visibility graphs and landscape visibility analysis. International Journal of Geographical Information Science, 15(3), pp. 221-237, 2001.

[10] Tsouchlaraki, A. \& Achilleos, G., Managing visual impacts through a GIS: visibility analysis for the design of a sanitary landfill site. Second International Conference on Waste Management and the Environment 'WASTE MANAGEMENT 2004', Wessex Institute of Technology (England), Rodos, Greece, 29 September-1 October 2004.

[11] Ying, S., Li, L., Mei, Y. \& Peng, X., Incremental terrain visibility analysis. Proceedings of SPIE - Geoinformatics 2006: Geospatial Information Science, October 2006.

[12] Sparkes, A. \& Kidner, D., A GIS for the environmental impact assessment of wind farms, http://gis2.esri.com/library/userconf/europroc96/PAPERS/PN26/PN26F.HTM, accessed 17 July 2007, 1996.

[13] Rios-Urban, M. \& Chasan, R., Uses of viewshed analysis models in planning and neighborhood preservation, http://gis2.esri.com/library/userconf/proc05/papers/pap2090.pdf, accessed 17 July 2007, 2005.

[14] Skov-Petersen, H. \& Snizek, B., To see or not to see: assessment of probabilistic visibility. 10th AGILE International Conference on Geographic Information Science 2007, Aalborg University, Denmark, 2007.

[15] Athanson, M., Modelling bullet trajectories on historic battlefields using exterior ballistics and target-oriented visibility. Proceedings of the Conference: Computer Applications and Quantitative Methods in Archaeology, CAA2006, Fargo, USA, 18-23 April 2006. 
[16] Albanese, J., Spatial and temporal analysis of bluestone quarries in New York State. Proceedings of the Northeastern Section - 40th Annual Meeting, 14-16 March, 2005.

[17] Franklin, Wm.R. \& Ray, C.K., Higher isn't necessarily better: visibility algorithms and experiments. Advances in GIS Research: Sixth International Symposium on Spatial Data Handling, eds T.C. Waugh \& R.G. Healey, Taylor \& Francis: Edinburgh, pp. 751-770, 1994.

[18] Kim, Y.H., Rana, S. \& Wise, S., Exploring multiple viewshed analysis using terrain features and optimisation techniques, http://eprints.ucl.ac.uk/archive/00000191/01/kim.pdf, accessed 17 July 2007.

[19] Jiang, B., A structural perspective on visibility patterns with a topographic surface. International Journal: Transactions in GIS, 9(4), pp. 475-488, 2005.

[20] Jude, S.R., Jones, A.P., Watkinson, A.R., Brown, I. \& Gill, J.A., The development of a visualization methodology for integrated coastal management. Coastal Management, 35, pp. 525-544, 2007.

[21] Coll, N., Fort, M., Madern, N. \& Sellares, J.A., Multi-visibility maps of triangulated terrains. International Journal of Geographical Information Science, 21(10), pp. 1115-1134, 2007.

[22] Achilleos, G. \& Tsouchlaraki, A., Visibility and viewshed algorithms in an information system for environmental management. Proceedings of the Conference: Management Information Systems 2004, Malaga, Spain, 2004.

[23] Achilleos, G., Considering elevation uncertainty for managing probable disasters. The 1st International Symposium on Geo-information for Disaster Management, Delft University of Technology, ISPRS, EuroSDR, AGILE, GIN, UN, Delft, the Netherlands, 21-23 March 2005.

[24] Kim, J.J., High target visibility analysis, ASPRS/ACSM, Annual Convention \& Exposition Technical Papers, Nevada, 25-28 April 1994, pp. 301-306, 1994.

[25] Felleman, P.J., Landscape visibility. Foundations for Visual Projects Analysis, John Willey \& Sons: NY, 1986.

[26] USDA Forest Service, The Visual Management System, Government Printing Office, Ag. Handbook 462, Washington, 1973.

[27] Tsouchlaraki, A., Assessment Methodology for Physical Relief Optical Value, PhD dissertation, Dept. of Rural \& Surv. Eng., NTUA, Athens, 1997 (in Greek).

[28] Tsouchlaraki, A., A quantitative model for evaluating landforms visual value. International Journal of Environmental Studies, Routledge - Taylor \& Francis Group, 62(3), June 2005, pp. 341-351.

[29] Mougiakakou, S.G., Tsouchlaraki, A., Cassios, C., Matsopoulos, G., Nikita, K.S. \& Uzunoglou, N., SCAPEVIEWER: preliminary results of a landscape classification system based on neural network technology. Ecological Engineering: The Journal of Ecotechnology, Elsevier Science Publishers BV, 24(1-2), pp. 5-15, 2005.

[30] Lynch, K., The Image of the City, MIT Press: Cambridge, 1985.

[31] Appleyard, D., Lynch, K. \& Meyer, J.R., The View from the Road, MIT Press: Cambridge, 1964.

[32] Cullen, G., The Concise Townscape, Architectural Press: London, 1976.

[33] Smardon, R., Castello, T. \& Egging, H., Urban visual description and analysis. Foundations for Visual Project Analysis, John Willey \& Sons: NY, 1986.

[34] Smardon, R. \& Karp, J., The Legal Landscape, VNR: NY, 1992. 